\title{
Contribution of multi-source remote sensing data to predictive mapping of plant-indicator gradients within Swiss mire habitats
}

\author{
Klaus Ecker • Lars T. Waser • Meinrad Küchler
}

Received: 2 November 2009/Accepted: 21 May 2010/Published online: 15 June 2010

(C) Springer Basel AG 2010

\begin{abstract}
Remote-sensing plays an important role in wetland monitoring on the regional and global scale. In this study we assessed the potential of different optical sensors to map floristic indicator gradients across complex mire habitats at the stand level. We compared traditional CIR photographs from RC30 cameras with modern digital ADS40 data and SPOT5 satellite images as well as finescale topo-structure derived from LIDAR data. We derived about 70 spectral and 30 topo-structural variables and evaluated their ability to predict the mean ecological indicator values of the vegetation across a sample of 7 mire objects. The airborne images (RC30, ADS40) and the LIDAR data were found to have a high potential for use in vegetation mapping; they explained on average $50 \%$ of the variation in observed ecological indicator values. The RC30 data slightly outperformed the less optimally collected ADS40 data. The LIDAR topo-structural variables showed equal overall predictive power as the airborne images, but they performed clearly better in predicting soil moisture, soil dispersion and light. Combining both airborne images and topo-structural data improved the
\end{abstract}

Responsible editor: Sabine Güsewell.

Electronic supplementary material The online version of this article (doi:10.1007/s00035-010-0070-4) contains supplementary material, which is available to authorized users.

K. Ecker $(\bowtie) \cdot$ L. T. Waser · M. Küchler

WSL, Swiss Federal Research Institute,

Zürcherstrasse 111, Birmensdorf 8903, Switzerland

e-mail: klaus.ecker@wsl.ch

L. T. Waser

e-mail: lars.waser@wsl.ch

M. Küchler

e-mail: meinrad.kuechler@wsl.ch predictions of all indicator values considerably. The combined use of these data sources is therefore recommended for use in fine-scale monitoring of priority habitats in nature conservation.

Keywords ADS40 - Aerial photography $\cdot$ Satellite imagery - LIDAR - Mire monitoring - Plant community . PLS-regression - RC30 - SPOT5 - Topography ·

Vegetation structure

Eignung von Fernerkundungsdaten aus mehreren Quellen zur räumlichen Modellierung floristischer Zeigerwertgradienten in Schweizer Moorhabitaten

Zusammenfassung Fernerkundung spielt eine bedeutende Rolle in der Dauerbeobachtung von Feuchtgebieten auf regionaler Ebene. Die vorliegende Studie untersuchte deren Eignung zur räumlichen Modellierung floristischer Zeigerwertgradienten auf der Bestandesebene komplexer Moorhabitate. Aus operationellen Gründen eines nationalen Beobachtungssystems waren nur landesweit abrufbare Datenquellen von Interesse. Traditionelle Infrarot-Luftbilder (RC30) wurden daher mit modernen ADS40 Luftbilddaten und SPOT5 Satellitenbildern verglichen. Zusätzlich standen erstmals präzise Gelände- und Oberflächenmodelle (LIDAR) zur Verfügung, welche die Relief- und Gehölzstruktur kleinsträumig abbilden. Der Sensorenvergleich erfolgte in sieben Moorhabitaten und bezüglich sieben Zeigerwerten (49 Testsituationen). Die Modelle basierten auf einem einheitlichen Satz von 100 erklärenden Variablen (70 spektrale und 30 topo-strukturelle Merkmale). Als Modelltyp wurde PLS-Regression gewählt. Die Analyse der sensor-spezifischen Modellbeiträge $\left(r_{\mathrm{cv}}^{2}\right)$ erfolgte mittels beschreibender Statistik und 
informellen multiplen Paartests (Vorzeichen-Rangsummen-Test). Die spektralen Luftbild- (RC30, ADS40) und Höhendaten (LIDAR) zeigten ein beträchtliches Prognosepotential. Die traditionellen RC30 Daten erwiesen sich den zeitlich weniger optimiert erhobenen ADS40 Daten als leicht überlegen. Die Relief- und Gehölzstrukturdaten bewiesen ein zumindest gleichwertiges Vorhersagepotenzial mit Vorteilen in der Modellierung von Feuchte, Dispersität und Licht. Alle Zeigerwerte profitierten von der Kombination beider Informationstypen. Die Zeigerwertspezifischen Verbesserungen variierten je nach spektralem Partner (RC30, ADS40, SPOT5). Einheitlich maximale Gewinne zeigten die ADS40 Daten, womit ihr individuelles Defizit gegenüber den RC30 Daten grossteils verfällt. Umgekehrt verbesserte die zusätzliche Spektralinformation besonders Modelle zu Bodenreaktion, Nährstoffgehalt und Humus. Die gewonnenen Erkenntnisse dienen der Potenzialabschätzung von Fernerkundungsdaten für vergleichbare Studien. Die Beiträge der individuellen oder paarweise kombinierten Datentypen lassen sich zudem ökologisch interpretieren. Sie deuten an, wie stark floristische Zeigerwertgradienten in Moorhabitaten von Reliefeigenschaften und Gehölzstruktur oder von anderen ökologischen Faktoren mit Bezug zu Biomasse und Produktivität bestimmt sind, welche nur von den Spektraldaten erfasst werden. Aufgrund der Übertragbarkeit der Methode auf weitere Lebensräume sollten die Resultate von allgemeinem Interesse sein, sowohl aus Sicht des lokalen Naturschutzmanagements als auch aus Sicht der operationellen Biotopbeobachtung im Naturschutz.

$\begin{array}{ll}\text { Abbreviations } \\ \text { CIR } & \text { Colour infrared } \\ \text { DTM } & \text { Digital terrain model } \\ \text { DSM } & \text { Digital surface model } \\ \text { LIDAR } & \text { Light detection and ranging } \\ \text { NIR } & \text { Near infrared } \\ \text { PLS } & \text { Partial least squares } \\ \text { VHSR } & \text { Very high spatial resolution }\end{array}$

\section{Introduction}

Wetland ecosystems are priority habitats in nature conservation and of great importance in the carbon and water cycles (Barducci et al. 2009). Hence, monitoring and mapping them is critical for their practical management and for the geographical representation of their ecosystem functions. Here, remote sensing has been very useful on regional and global scales. Today, modern high resolution spectral sensors, such as satellite data Quickbird and
Ikonos or multi- and hyperspectral airborne datasets, and active remote sensing techniques, such as synthetic aperture radar (SAR) or light detection and ranging (LIDAR), also provide ways of mapping wetlands on local scales, as numerous research papers have shown. Korpela et al. (2009) analysed pure LIDAR data to map mire vegetation types, their main nutrient levels and dominant tree species. Others have used hyperspectral data to model biological parameters such as humification (McMorrow et al. 2004), green biomass (Barducci et al. 2009) or moisture condition (Harris and Bryant 2009). LIDAR and hyperspectral data have been combined in assessing such wetland characteristics as surface roughness (Straatsma and Baptist 2008), fractional tree cover (Waser et al. 2008a), individual tree species (Waser et al. 2008b), monotypical stands (Gilmore et al. 2008) and heterogeneous plant communities (Johansen et al. 2007; Verrelst et al. 2009).

Beside the rapid multiplication of such products, the new data face serious constraints from scene-specific noise due to reflectance angles, phenology and atmospheric blurring. Active sensors such as LIDAR are less affected by recording conditions, but still reflect the annual growing and foliation cycle. Systematic studies that integrate scenes from multiple sites or time stages suffer most from these variations, so particular effort has to be devoted to deal with them. When the mapping of semi-natural habitats is aimed at, empirical methods relating the optical data to surface measurements are typically used in this context. Moreover, when subtle vegetation transitions are the features of interest, costly field-data calibration of each individual scene and rigorous testing of the retrieved vegetation properties is indispensable. As a consequence, the new sensor techniques are hardly used in operational applications for nature conservation monitoring (Bunce et al. 2008; MacKay et al. 2009). Where they have been used, they have still been supported by field work and visual interpretation, e.g. in the semi-automated updating of Natura 2000 habitat maps (Alexandridis et al. 2009) and the interactive post-processing of land-use and land-cover maps from the GlobWetland project (Jones et al. 2009). Programs supported by tight budgets need to operate on less advanced, but existing remotely sensed data that are locally and temporally replicable (MacAlister and Mahaxay 2009). Such data are also the only option in retrospective vegetation analysis for addressing those time periods when modern remote sensing techniques were not yet available.

The present study was carried out in the framework of the Swiss mire monitoring program (Grünig et al. 2005; Ecker et al. 2008), which was designed to detect floristic changes in mire habitats of national importance. To satisfy the ambitious demand for robust but still sensitive change 
estimates for Switzerland, the program combines repeated vegetation recording in a nation-wide sample of 125 mire objects with full habitat mapping based on remote sensing techniques. Because of the dominant role of the field campaign, the monitoring uses existing data sources which have been regularly updated for the whole nation by the Swiss Federal Office of Topography. The spectral information of the first mapping period in 1990s originated from airborne CIR photographs taken with analogue film RC30 cameras. Such cameras were widely used in traditional airborne imaging (Cramer 2005), but recently they have faced competition from digital sensors. The Swiss Federal Office of Topography changed to working with digital data from airborne ADS40 sensors in 2008 (Kellenberger and Nagy 2008). The digital device is supposed to be spectrally and radiometrically superior to the analogue RC30 cameras (Petrie and Walker 2007). A satellite SPOT5 mosaic has also recently become available for the whole area of Switzerland. In addition to the spectral data, fine-scale topo-structural information has been obtained with LIDAR technology.

Because mire ecosystems are characterised by continuous gradients varying at short distances in a complex way, the usual classification system of remotely sensed data was not appropriate. In general, mapping vegetation categories produces satisfactory results if applied to scales and ecosystems where discrete patterns appear. The simplification is less appropriate within semi-natural habitats where the transitions between environment and species assemblages are usually continuous. Even methods that allow multipleclass memberships assume the existence of distinct habitat categories, such as ideal species assemblages (Schmidtlein and Sassin 2004). Since mire patterns are determined by the factors hydrology, soil, climate, land use and interacting vegetation (Rydin and Eglum 2006), the Swiss mire monitoring has primarily focused on these gradients. For the field measurements, we derived averaged plant indicator values (Ellenberg et al. 1992) from vegetation relevés and used them as a practical estimate of the variables of interest. The values are based on a well-established expert system widely used in Central Europe for bio-indication of a range of floristic gradients associated with factors such as temperature, soil acidity, humus content, plant available nutrients, soil moisture and light supply (Diekmann 2003).

Remote sensing techniques were applied to predictively map those values across the 125 sample mires of the monitoring. The resulting maps were primarily used for habitat stratification to refine samples in the second survey and to convert the proportional field samples into local, regional and national estimates (Graf et al. 2007). Besides they were used for full area change detection within a habitat via bi-temporal map comparison (Küchler et al. 2007). The predicted maps are not only of great interest for the fine-scale assessment and monitoring of wetland ecosystems. Since they are ecologically meaningful, directly interpretable and transferable across sites due to the fielddata calibration, they are of general relevance for local management and regional planning of priority habitats in nature conservation. Some attempts have already been made to predictively map such gradients across semi-natural habitats (Küchler et al. 2004; Schmidtlein and Sassin 2004; Schmidtlein 2005; Ecker et al. 2008). Those predictive models were either based on multi- or hyperspectral imagery, but sensor comparison within the same habitat and study design was not an object of those studies.

The goal of the present study was to assess the sensor effect on the performance of such empirical models. We tested the potential of the existing spectral (RC30, ADS40, SPOT5) and topo-structural (LIDAR) data sets to predict the floristic gradients in a set of seven mire habitats. Three data sources (ADS40, SPOT5, LIDAR) had never been linked to plant-indicator gradients before. The spectral and topo-structural data sets were tested individually and in mutual combination to assess their unique and joint model contributions. The partitioning assisted in the ecological interpretation of the plant-indicator gradients.

We expected both airborne sensors (RC30, ADS40) to clearly outperform the satellite sensor (SPOT5) in all gradients mapped. The SPOT5 sensor can map mires over large areas with its broad swath width of $60 \mathrm{~km}$, so its relative performance, both individually and in combination with topo-structure, was still of interest. Among the airborne spectral sensors, we hoped that the modern ADS40 system would be as good as or even outrange the labourintensive RC30 sensor. It was expected that including topostructural information would further improve the mapping of such plant-indicator gradients as soil moisture and light supply.

\section{Materials and methods}

\section{Study areas}

The mire objects to be mapped are part of a nation-wide stratified random sample, which was drawn in the course of the Swiss mire monitoring program (Grünig et al. 2005). Due to the limited extent of the remotely sensed images tested in this study, analyses were restricted to seven sample objects in the region of lake Walensee where all the data sources (RC30, ADS40, SPOT5 and LIDAR) overlap (Fig. 1).

The study sample is representative of the main mire types in Switzerland: minerotrophic fens with mobile groundwater, ombrotrophic raised bogs and transitional 
Fig. 1 Sample of the Swiss mire monitoring program (125 mires, black dots). The seven objects analysed in this study are located on the north-eastern slopes of the Swiss Alps (numbered dots)

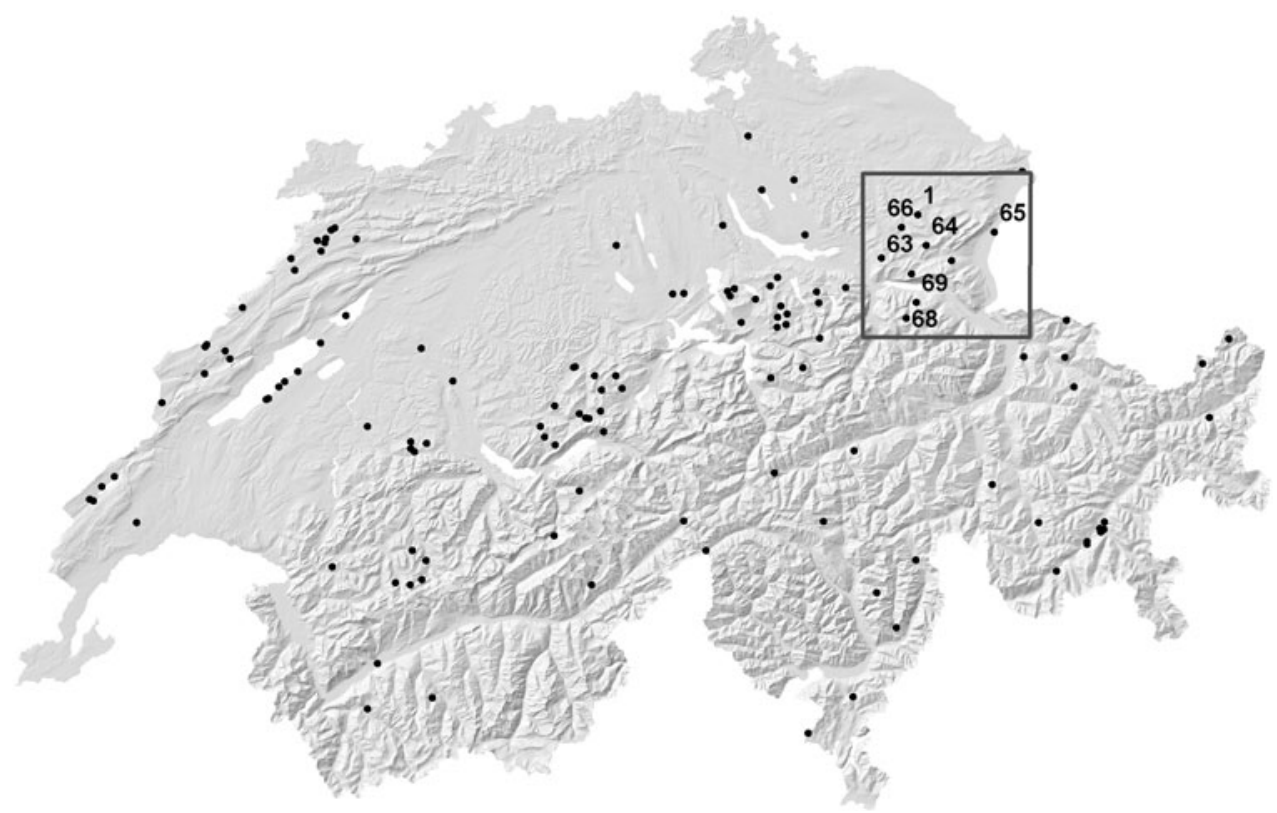

mires partly dependent on the ground-water supply and precipitation. Three objects represented pure formations of these main types, whereas the majority (four sites) consisted of a complex pattern of fen, bog and transitional mire. All objects were embedded in cultural landscapes. Habitat heterogeneity was pronounced on the scale of micro-topography.

\section{Field sampling}

For this analysis we used vegetation relevés from the second survey of the Swiss mire monitoring program. These data were recorded in summer 2006 with the exception of object 63 , which was surveyed in 2003. The records comprise a full list of vascular plants and bryophytes, including abundance data.

The data were collected from a sample of homogeneous vegetation patches which were delineated on RC30 images in a stereo-microscope. The sampling procedure applied was adaptive stratified random sampling: For the first survey a proportional sample was drawn based on colour classes derived from RC30 images. For the second survey the initial sample was sub-sampled to proportionally represent the major community types of a study site (about 40 categories all over Switzerland). The latter were derived from indicator gradients which were predictively mapped from the data of the first survey. For defining the proportions we considered the area and mire character of those categories.

Due to the adaptive procedure the mire samples were assumed to optimally reflect the spatial heterogeneity of their site. The seven habitats covered areas from 5.7 to 48 ha. Their segmentation produced total populations of
159 to 1,444 vegetation patches. The average patch size varied between 275 and $409 \mathrm{~m}^{2}$ with the exception of the coarse-structured object 63 . There the total population amounted to 62 patches with an average patch size of $1,200 \mathrm{~m}^{2}$. The sample sizes employed to describe the individual sites ranged from 86 to 121 patches. Again object 62 deviated with a low number of 55 recorded patches.

Peatland patterns are composed of plant assemblies and peat that have developed in response to subtle environmental gradients and land use. The principal environmental determinants are tree cover, wetness-aeration and acidity gradients. Further variations are caused by nutrients and other chemical or physical factors (Rydin and Eglum 2006). As measuring the factors in the field is cost-intensive and sophisticated, we used mean plant indicator values derived from presence/absence vegetation records to indirectly assess the gradients of soil moisture, light, temperature, nutrients, soil reaction, humus content and dispersity.

These quasi-continuous measurements have proven to be an effective predictor of ecological conditions (Diekmann 2003). The indicator values assigned to vascular plants by Ellenberg for Central Europe (Ellenberg 1974; Ellenberg et al. 1992) and adapted by Landolt for Switzerland (Landolt 1977) are the most commonly used. In this study we calculated $10 \%$ trimmed means of numerically adjusted Landolt indicator values. The adjustment of the Landolt values was done through weighted averaging of 8,000 vegetation records from the Swiss Mire Monitoring Program. The new values covered a potential range from 1 to 6 and showed better model performance than the original ones (FeldmeyerChriste et al. 2007). 
Remotely sensed data sources

Two types of data were used: (1) elevation data and (2) spectral information. Elevation data were primarily provided by high precision digital surface and terrain models interpolated from airborne scanning LIDAR data (first and last pulse) with a ground resolution of $2.5 \mathrm{~m}$ (DSM2.5, DTM2.5). The vertical accuracy was stated with a standard deviation of 0.5 and $1.5 \mathrm{~m}$ (open terrain and afforested terrain) for the DSM and $0.5 \mathrm{~m}$ for the DTM. The data were taken under snow-free conditions. The time lag between the flight dates and the recording of the vegetation was 1-4 years. To account for processes acting on larger scales, we additionally supplied a digital terrain model with a ground resolution of $25 \mathrm{~m}$ (DTM25).

The spectral information originated from three different sensor types comprising two airborne Leica cameras (analogue film RC30 and digital scanner ADS40) and the space-borne SPOT5. The available multi-spectral imagery differs in terms of pre-processing, swath width (footprint), spatial resolution, number of colour bands, colour spectrum and colour depth. The sensor-specific characteristics are given in Table 1.

The analogue film RC30 data and corresponding CIR orthophotos tested in this study had the best spatial resolution but required high processing efforts in photogrammetry. For this, overlapping analogue aerial photographs were taken at a scale of about 1:5,000 in the early summer before the first hay was cut and 1 year before the field survey. The analogue photographs had to be scanned at a very high spatial resolution, geographically referenced (based on accurate ground control points measured in the field), stitched together (due to the small field width) and orthorectified.

The RC30 images were compared with digital ADS40 orthophotos of $50 \mathrm{~cm}$ ground resolution. The latter data were collected during the whole vegetation period and in a broader time slot of the day, which means that they were less controlled for interfering effects from phenology and adverse sun position. The ADS40 images are based on the first generation of sensor heads (SH40) which provide images from two different angles. They record four bands in nadir direction (red, green, blue and panchromatic) and three bands in forward direction (NIR, red, green). To mimic the full potential of the newest generation of sensor heads (SH52) which cover all four spectral bands (NIR, red, green, blue) in one (nadir) viewing angle, we reorganized the SH40 images and supplied an artificial fourband image composed of two forward looking bands (NIR and red) and two nadir looking ones (green and blue). These images were assumed to be radiometrically superior to the RC30 data, but they may have deficiencies in terms of spatial resolution, acquisition angles and dates, that might hamper their mapping potential.

The SPOT5 data originate from three different scenes recorded between late August and September 2005. They
Table 1 Description of the spectral data sets employed

Aspects expected to be clear advantages $(+)$ or disadvantages $(-)$ in the predictive mapping of averaged plant indicator values are marked accordingly (+/-)

\begin{tabular}{llll}
\hline & \multicolumn{2}{l}{ Spectral sensors } & \\
\cline { 2 - 3 } & Analogue RC30 & Digital ADS40 & Digital SPOT5 \\
\hline Flight data & & & \\
$\quad$ Height (km) & $0.7-1.2$ & 2.4 & $830(-)$ \\
Width of view (km) & 1.2 & 7.6 & $60(+)$ \\
Time lag to ground truth (year) & 1 & $1(2)$ & $1(2)$ \\
Months & $6-8$ & $8-9$ & No \\
Controlled conditions & Yes (+) & No & na \\
Colour spectrum (nm) & & & $500-590$ \\
Blue & na & $430-490(+)$ & $610-688$ \\
Green & $400-600$ & $535-585$ & $780-890$ \\
Red & $400-700$ & $610-660$ & $10(-)$ \\
NIR & $400-900$ & $835-885$ & 256 \\
Resolution & & & $2-3(-)$ \\
Spatial (m) & 0.32 & 0.5 & No \\
Radiometric (steps) & 256 & $4,096(+)$ & \\
Accuracy & & $0.5-1$ & No \\
$\quad$ Planimetric (RMS) (m) & $0.05-0.25$ & & \\
Pre-processing effort & Yes (-) & &
\end{tabular}


suffer from low planimetric accuracy and have the lowest spatial resolution by far. In addition the colour quality is negatively affected by increased atmospheric blurring. Apart from these limitations, the SPOT5 sensor can map mires over larger areas due to a broad swath width of $60 \mathrm{~km}$, and its spatial resolution of $10 \mathrm{~m}$ is still below the average patch size of our mire plots.

\section{Predictor variables}

The remotely sensed data described above offered a multitude of point and pattern information on and below the patch level. To reduce reflectance angle effects and to condense the multi-band data, band-ratio and bandfusion techniques were applied. Secondary features were computed to filter meaningful information from the spatial configuration of the pixels. To extract the information at the plot level we calculated patch-level statistics (Jensen et al. 2008) retrieving the mean value, the standard deviation or proportions in the case of categorical variables. The resulting variables (176 spectral and 121 topo-structural characteristics) were transformed following the first-aid transformations (Mosteller and Tukey 1977) to improve the linear relationship of the regression models. Accordingly, we used $\log$ transformation for absolute values, square root transformation for count data and arcus-sinus transformation for proportions. Next, variable reduction was performed to exclude the most redundant but less powerful predictors. The predictive character of a variable was determined across all study mires thus accounting for all model situations.

The pre-selection resulted in 100 variables containing 68 spectral and 32 topo-structural variables. The ADS40 images yielded an additional four spectral variables from the blue colour band, adding up to 72 spectral or 104 overall predictors. The spectral predictor set comprised upscaling measures (mean, standard deviation and proportion) of colour classes and individual colour bands, both derived from raw data, as well as from band ratios. Additionally, four different spectral vegetation indices (mean, standard deviation) were retained, including: NDVI (Richardson and Wiegand 1977; Wiegand et al. 1991), a modified EVI (Huete et al. 2002) using the green band instead of blue for the atmospheric correction (Green-EVI), and a modified DVI (Richardson and Everitt 1992) using band ratios (RDI) and MSAVI2 (Qi et al. 1994). The final topo-structural predictor set included primary features (12 attributes), such as elevation, northness, eastness, slope angle and curvature. Vegetation structure is reflected by three canopy height classes (open land, bushes and trees). The group of secondary features (20 attributes) included proxies for erosion, wetness, insolation and topographic exposure (see Appendix S1 for a detailed description of the final predictors).

Data analysis

To assess the heterogeneity of each mire site regarding ecological conditions, we plotted the ranges of ecological indicator values observed at the seven study sites. We also calculated pair-wise correlations between indicator values to assess how model predictions might be correlated to each other.

Model selection was done through a two-fold variable reduction process designed to optimally map all individual habitat situations from the same source predictor set. We first isolated, as described above, about 100 predictors which showed high predictive potential but low redundancy across all study sites. The second reduction step was part of the individual modelling process. Based on preliminary tests comparing several methods to reduce the number of input variables, we chose partial least squares regression (PLS, Wold et al. 2001) to build the predictive models, as this method yielded the highest predictive power. The components incorporated in the regression were restricted to five latent variables. This was found to be sufficient for predicting indicator values optimally in a grassland study based on hyperspectral imagery data (Schmidtlein and Sassin 2004).

We fitted four partial models (referred to as RC30, ADS40, SPOT5 and TOPO) and three full model versions (combining topo-structural data and spectral predictors, referred to as $\mathrm{RC} 30+, \mathrm{ADS} 40+$, SPOT5+) to predict seven indicator gradients across each of the seven mires studied. This resulted in 49 mapping situations per model type or 343 predicted maps in total. Prediction quality was addressed by calculating the squared Pearson's productmoment coefficient $\left(r_{\mathrm{cv}}^{2}\right)$ from tenfold cross-validation.

The prediction qualities of the seven models were compared pairwise across the seven mires (for each indicator value) using Wilcoxon signed rank tests. Given the nature of the seven predictor sets (4 partial and 3 full model types), we were interested in 15 comparisons per indicator value. We applied double one-sided testing and retained the lower $\mathrm{p}$ value for each pair of models. Due to the problem of multiple testing (Dudoit and van der Laan 2008), the test results presented do not conform to the stringent significance rules of statistical testing. According to the classic Bonferroni correction (Miller 1981), the $0.05 \%$ significance level had to be adjusted to $0.003 \%$ in order to account for the multiple probabilities of false rejection. Because the statistical power of one-sample Wilcoxon tests based on seven observations was low ( $P$ values did not drop below 0.008), small values were still interpreted as informal exploratory measures for potential differences. 


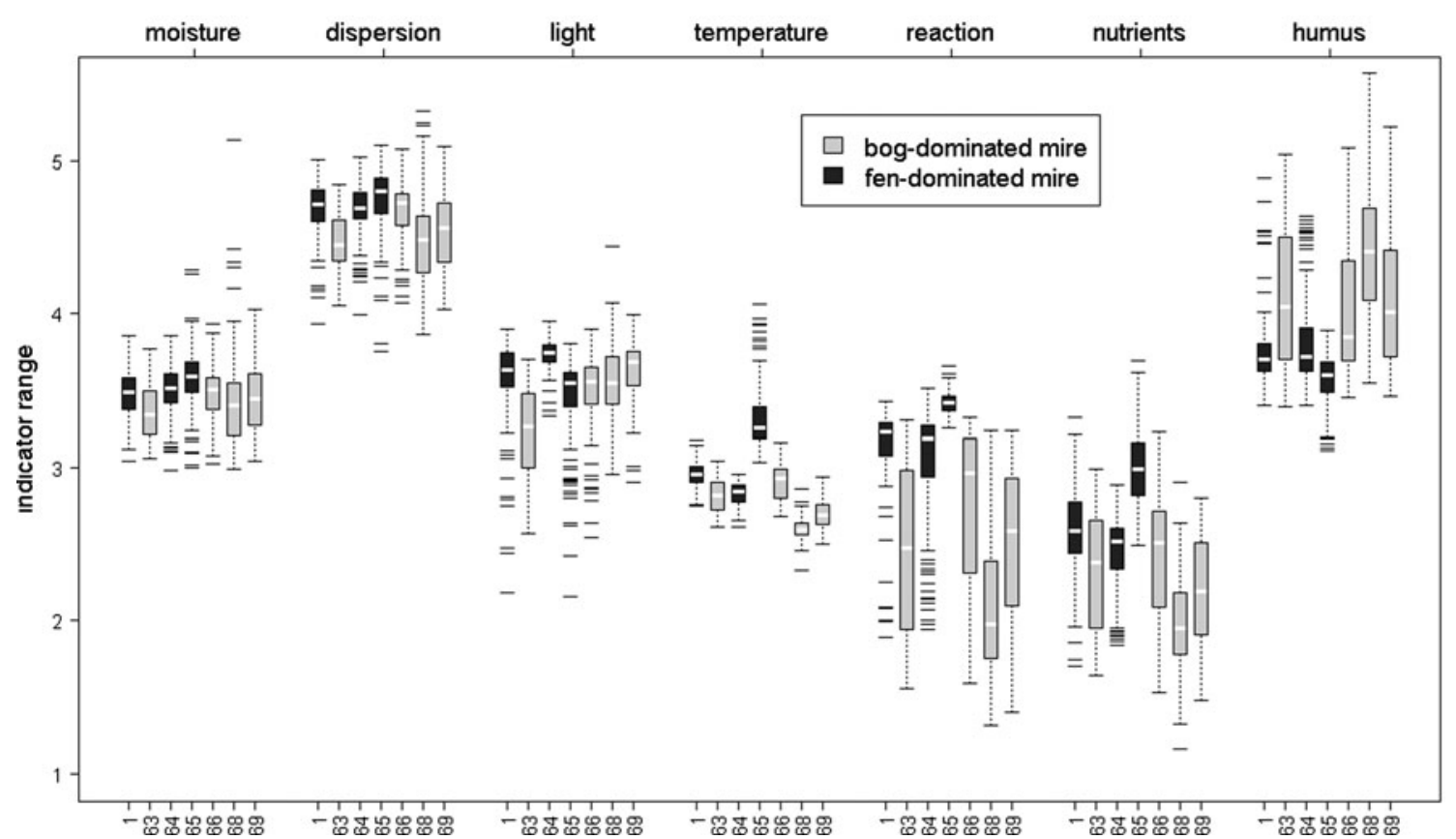

Fig. 2 Box plots of averaged plant indicator values. The numbers on the $x$-axis denote the mire objects sampled. Fen-dominated objects were 1, 64, 65; bog-dominated objects were $63,66,68,69$

\section{Results}

Observed plant-indicator gradients

The mires studied showed clear differences in their observed plant-indicator gradients (Fig. 2). The longest gradients and interquartile ranges (IQR) were detected for the soil reaction, nutrients and humus content in objects with large fractions of raised bogs. In contrast, the fen dominated objects showed rather short plant-indicator gradients across all indicator values. In addition, these gradients tended to be located near the centre, with the exception of dispersion showing extreme values. The pure fen object (65) from the colline belt differed most from the bog objects. This mire is characterized by clearly warmer but less nutrient-poor, less acidic and less humous floristic conditions. The other fen-dominated objects $(1,64)$ represented intermediate positions.
Depending on the study object, the indicator values were alternately correlated with each other. Among the pooled objects (Table 2), strong overall correlations $(r>0.8)$ were observed between the soil reaction, nutrients and humus, and between moisture and dispersion. Furthermore, temperature was highly correlated to nutrients. Thus we can distinguish three gradient groups that are rather independent of each other: light; moisture and dispersion; soil reaction, nutrients, humus and, less consistently, temperature. The latter gradient varies on larger scales. The predictive performance of the individual gradients widely reproduced these groupings, as being presented in the following sections.

Predictive mapping and sensor comparison

Mapping the full variety of mire types (Fig. 2) based on differing recording conditions produced large variations in
Table 2 Correlation matrix of the averaged indicator values (7 mire sites pooled)

\begin{tabular}{lrrrrrr}
\hline & Moisture & Light & Temperature & Reaction & Nutrients & Humus \\
\hline Light & 0.49 & & & & & \\
Temperature & 0.25 & -0.25 & & & & \\
Reaction & -0.01 & 0.09 & 0.69 & & & \\
Nutrients & -0.18 & -0.28 & 0.82 & 0.88 & & \\
Humus & 0.35 & 0.11 & -0.59 & -0.93 & -0.92 & \\
Dispersion & 0.90 & 0.65 & 0.23 & 0.12 & -0.13 & 0.23 \\
\hline
\end{tabular}


Fig. 3 Box plots showing the relative predictive power $\left(r_{\mathrm{cv}}^{2}\right)$ of seven predictor sets (partial: RC30, ADS40, SPOT5; TOPO; and combined with TOPO: $\mathrm{RC} 30+, \mathrm{ADS} 40+$, SPOT5+). The model performance is given for mapping individual plantindicator gradients and for the pooled results (all IVs). The boxes reflect the variation of the seven mire objects tested

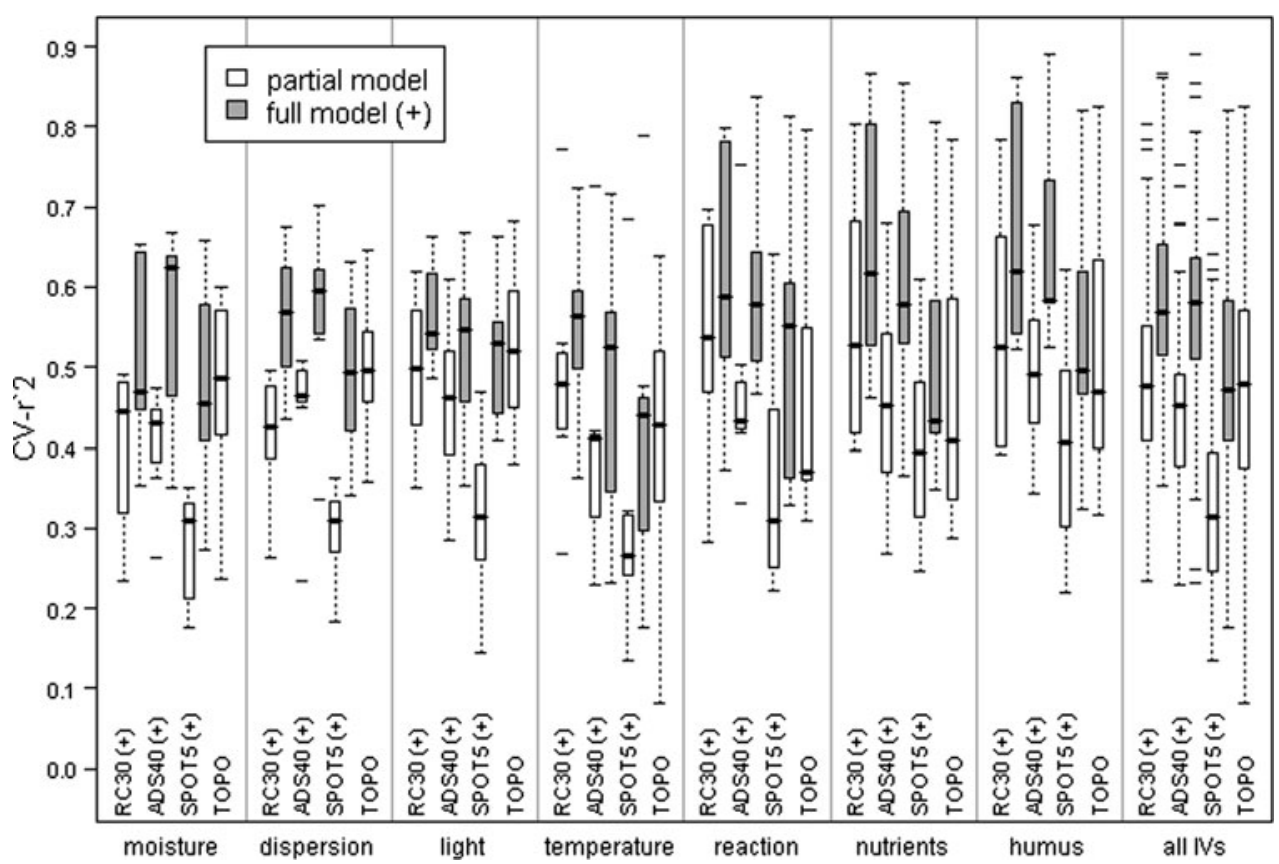

the performance of a predictor set (Fig. 3, see Appendix S2 in the supplementary material for the individual performance measures of the underlying $7 \times 7 \times 7=343$ models). Despite the big overlaps between the boxes, Fig. 3 shows the big picture and the most extreme performance results. Thus we observed an overall marked increase in the model performance when combining the spectral data sets with topo-structure (see section "all IVs" in Fig. 3). According to these summed-up boxes we obtained the best model results (overall median $r_{\mathrm{cv}}^{2}$ values of about 0.58) with both full airborne model versions (RC30+, ADS40+). In contrast, the satellite-based full model (SPOT5+) did not score better than the partial RC30 and TOPO models, and only slightly better than the partial ADS40 model. Accordingly, the partial SPOT5 model showed by far the lowest overall median prediction quality. Looking at the individual model results, we observed similar maxima of the $r_{\mathrm{cv}}^{2}$ values with all full models $(\mathrm{RC} 30+, \mathrm{ADS} 40+, \mathrm{SPOT} 5+)$. The values varied between 0.87 (RC30+ model for nutrients in object 69), 0.89 (ADS40+ model for humus in object 63) and 0.82 (SPOT5+ model for humus in object 63). The minimum values ranged from 0.35 (RC30+ model for moisture in object 65) over 0.23 (ADS40 + model for temperature, object 64) to low 0.18 (SPOT5+ model for temperature, object 64).

Informal multiple pair tests (Wilcoxon signed rank tests) were applied to rank the source-specific contributions for each individual indicator. The results (Table 3) can be summarized and ordered as follows: Among the pure spectral models, the SPOT5 model was clearly outperformed by the airborne-data-based models. The deficiencies of the
SPOT5 sensor were less heavily pronounced with nutrients and humus. Among the airborne data, the RC30 model did slightly better than the ADS40 model across all indicator values except for moisture and dispersion. The advantages of the RC30 data were most apparent for light and temperature.

Next, we compared the spectral models with their topostructural counterpart (TOPO). None of the spectral models clearly outperformed the TOPO model. The RC30 data had some advantages when predicting reaction, nutrients, humus and temperature. Conversely, the TOPO model turned out to be clearly superior to the spectral models (although less pronounced with RC30) for mapping moisture, dispersion and, most markedly, light. Apart from this specific strength, the TOPO model outperformed the SPOT5 model on all indicator values.

Combining both data types clearly increased the predictive power of all spectral predictor sets, no matter which indicator value was addressed. Interestingly, the ADS40 based models benefited most from the additional topostructural information. Conversely, the TOPO models showed similar benefits across all indicator values from adding airborne spectral data, with the exception of predicting light, for which the ADS40 data provided no additional information at all. The complementary contributions were most pronounced for reaction, nutrients and humus. However, including the SPOT5 data led to hardly any additional information than obtained with topo-structure alone.

When testing the full models alone, the SPOT5+ model again performed worst throughout indicator values. In contrast to the partial model, the shortcomings of the 
Table 3 Multiple pair tests for comparing selective model versions upon mapping performance ( $r_{\mathrm{cv}}^{2}$ values) of individual plant-indicators
The italicized values indicate the direct comparisons of the full and related partial models. The rest refers to comparisons among the partial and among the full models, respectively. The computation of the $p$ values is based on Wilcoxon signed rank tests. The table retains the lower value from double onesided testing. The letter " $\mathrm{r}$ " denotes the resulting order of the paired models. Accordingly, $p$ values followed by this letter indicate that the model listed in the row is better. Multiple testing is problematic, so the values have to be interpreted as quantitative measures for the differences in the data but do not represent statistical inference

\begin{tabular}{|c|c|c|c|c|c|c|}
\hline & RC30 & ADS40 & SPOT5 & TOPO & $\mathrm{RC} 30+$ & ADS40+ \\
\hline \multicolumn{7}{|l|}{ Moisture } \\
\hline ADS40 & $0.47 \mathrm{r}$ & & & & & \\
\hline SPOT5 & 0.02 & 0.02 & & & & \\
\hline TOPO & $0.19 \mathrm{r}$ & $0.05 \mathrm{r}$ & $0.01 \mathrm{r}$ & & & \\
\hline RC30+ & $0.04 r$ & & & $0.08 r$ & & \\
\hline ADS40+ & & $0.01 r$ & & $0.02 r$ & $0.18 \mathrm{r}$ & \\
\hline SPOT5+ & & & $0.01 r$ & $0.15 r$ & 0.15 & 0.02 \\
\hline \multicolumn{7}{|l|}{ Dispersion } \\
\hline ADS40 & $0.19 \mathrm{r}$ & & & & & \\
\hline SPOT5 & 0.03 & 0.02 & & & & \\
\hline TOPO & $0.07 \mathrm{r}$ & $0.05 \mathrm{r}$ & $0.02 \mathrm{r}$ & & & \\
\hline $\mathrm{RC} 30+$ & $0.02 r$ & & & $0.04 r$ & & \\
\hline ADS40+ & & $0.01 r$ & & $0.02 r$ & 0.47 & \\
\hline SPOT5+ & & & $0.02 r$ & $0.71 r$ & 0.11 & 0.02 \\
\hline \multicolumn{7}{|l|}{ Light supply } \\
\hline ADS40 & 0.04 & & & & & \\
\hline SPOT5 & 0.01 & 0.02 & & & & \\
\hline TOPO & $0.08 \mathrm{r}$ & $0.02 \mathrm{r}$ & $0.02 \mathrm{r}$ & & & \\
\hline $\mathrm{RC} 30+$ & $0.01 r$ & & & $0.04 r$ & & \\
\hline ADS40+ & & $0.02 r$ & & 0.47 & 0.08 & \\
\hline SPOT5+ & & & $0.02 r$ & 0.34 & 0.04 & 0.34 \\
\hline \multicolumn{7}{|l|}{ Temperature } \\
\hline ADS40 & 0.02 & & & & & \\
\hline SPOT5 & 0.01 & 0.02 & & & & \\
\hline TOPO & 0.19 & 0.53 & $0.11 \mathrm{r}$ & & & \\
\hline $\mathrm{RC} 30+$ & $0.02 r$ & & & $0.02 r$ & & \\
\hline ADS40+ & & $0.08 r$ & & $0.08 r$ & 0.04 & \\
\hline SPOT5+ & & & $0.02 r$ & 0.47 & 0.02 & 0.08 \\
\hline \multicolumn{7}{|l|}{ Nutrients } \\
\hline ADS40 & 0.23 & & & & & \\
\hline SPOT5 & 0.04 & 0.15 & & & & \\
\hline TOPO & 0.23 & $0.29 \mathrm{r}$ & $0.15 \mathrm{r}$ & & & \\
\hline RC30+ & $0.02 r$ & & & $0.01 r$ & & \\
\hline ADS40+ & & $0.01 r$ & & $0.01 r$ & 0.53 & \\
\hline SPOT5+ & & & $0.02 r$ & 0.23 & 0.01 & 0.02 \\
\hline \multicolumn{7}{|l|}{ Soil reaction } \\
\hline ADS40 & 0.23 & & & & & \\
\hline SPOT5 & 0.02 & 0.05 & & & & \\
\hline TOPO & 0.19 & 0.41 & $0.11 \mathrm{r}$ & & & \\
\hline RC30+ & $0.02 r$ & & & $0.01 r$ & & \\
\hline ADS40+ & & $0.01 r$ & & $0.01 r$ & $0.5 \mathrm{r}$ & \\
\hline SPOT5+ & & & $0.02 r$ & 0.53 & 0.19 & 0.04 \\
\hline \multicolumn{7}{|l|}{ Humus } \\
\hline ADS40 & 0.29 & & & & & \\
\hline SPOT5 & 0.11 & 0.15 & & & & \\
\hline TOPO & 0.34 & $0.23 \mathrm{r}$ & $0.11 \mathrm{r}$ & & & \\
\hline RC30+ & $0.02 r$ & & & $0.02 r$ & & \\
\hline ADS40+ & & $0.01 r$ & & $0.01 r$ & $0.47 \mathrm{r}$ & \\
\hline SPOT5+ & & & $0.04 r$ & $0.41 r$ & 0.01 & 0.02 \\
\hline
\end{tabular}


extended version were most distinct for mapping nutrients and humus. Among the airborne sensors, the ADS40+ model was mostly as good as the RC30+ counterpart. Its slight superiority in predicting moisture was offset by it being less good at mapping light and temperature. Thus, unlike the SPOT5 data, the extended airborne models reproduced the individual strengths of their spectral sensors.

\section{Discussion}

The present study compared the potential of four optical sensors to empirically predict plant indicator values across seven mire habitats. The stand-level mapping technique was applied by the Swiss mire monitoring program to refine the proportional samples of 124 mire habitats and to project observed changes statistically onto the regional and national scale (Graf et al. 2007). Küchler et al. (2007) tested the resulting maps for full area change detection within habitats where conservation or restoration measures had been taken. There the maps provide comprehensible information of practical relevance for local management.

\section{Methods for variable retrieval from optical data}

Currently, a variety of air- and space-borne optical sensors are tested to cost-efficiently map ecosystem properties on the fine scale. However, significant limitations result from the complex photon-vegetation interactions which affect the reflectance pattern of the vegetation. The variations arise from factors such as sun-sensor-canopy geometry, structure, the spectral interference from understory, soil and surrounding objects or simple phenology. Consequently, empirical methods have been used to relate the optical data to surface measurements. In this study we used PLS regression models to relate the remotely sensed data to plant indicator gradients measured in the field. Such empirical methods are straightforward and simple, but the empirical relationship is limited to the particular site and time for which it was established (Baret and Guyot 1991; Malenovsky et al. 2009). Therefore, cost-intensive calibration is required for each individual recording situation.

Physical methods have been proposed as an alternative to the empirical approaches to solve the given lack of generality. These methods are based on physical reflectance models which simulate the virtual transfer of photons within the canopy based on physical rules (Malenovsky et al. 2009). Since model parameters are determined in the model inversion mode through the best match between the simulated and remotely sensed reflectance, this method does not depend on the impractical surface measurements. Being based on physical laws the retrieved vegetation properties are of some general nature. However, there is a frequent trade-off between model universality and accuracy. Moreover, it requires extensive computational effort (Jacquemoud et al. 2000) and a priori knowledge to regularize the model inversion process (Atzberger 2004). Finally, the specific assumptions of the physical model limit its applicability to only certain distinct vegetation types or geographical arrangements. Typical applications address scales and landscapes, where distinct features appear such as intensively cultivated land or mono-dominant forest patterns (Houborg et al. 2007). Thus physical retrieval methods will be hardly applicable for fine-scale operational mapping of semi-natural habitats, where the features of interest are continuous and a good deal more heterogeneously structured.

State of the art in predictive mapping of plant indicator values

LIDAR, ADS40 and SPOT5 data had not been used for mapping indicator values prior to this study. Previous research on predicting plant-indicator gradients was based on hyperspectral data (Schmidtlein and Sassin 2004; Schmidtlein 2005) or on RC30 images (Küchler et al. 2004; Ecker et al. 2008). The hyperspectral data showed a high potential for mapping the floristic properties moisture, nutrients and soil reaction across shadow-masked meadows and open land pastures. The related two case studies mentioned above used 35 and 46 stratified relevés, respectively, to calibrate PLS regression models. The subsequent variances explained ranged from 58 to $76 \%$ according to $r_{\mathrm{cv}}^{2}$ measures. These results were better than the corresponding prediction qualities (median $r_{\mathrm{cv}}^{2}$ of the seven study mires) of our best performing spectral model (RC30: 0.44-0.54), but the accuracy values of certain spectral models were comparable, e.g. with the RC30 model for nutrients in object $69\left(r_{\mathrm{cv}}^{2}=0.80\right)$; and with the ADS40 model for soil reaction in object $63\left(r_{\mathrm{cv}}^{2}=0.75\right)$. Adding LIDAR information to the spectral predictor set markedly increased the model qualities. The accuracy values (e.g. ADS40+: median $r_{\mathrm{cv}}^{2}=0.58-0.62$ ) remained below those reported in the studies cited above, but the individual objects 63, 69 and 64 were predicted even better (ADS40+ and RC30+ models: $r_{\mathrm{cv}}^{2}=0.64-0.87$ ).

The studies are, however, difficult to compare as the sensor effect interferes with habitat and sample aspects. The field plots of the open grassland studies were small in size (below $25 \mathrm{~m}^{2}$ ), shadow-masked and stratified in the field according to floristic composition, and thus had optimal homogeneity. In contrast, the field records used in our study were based on image segmentation and stratified random sampling. Consequently, the patches represented plots of much larger size (the average patch size per object was above $270 \mathrm{~m}^{2}$ ) and higher vegetation complexity (including trees, shrubs and shadows). 
Relevance of the predicted indicator values

According to a personal communication of Landolt on the explanatory power of mean indicator values, individual observations have to differ more than 0.2 to indicate a real difference or change. In this paper the full airborne models resulted median $95 \%$ error quantiles below 0.21 across all indicator variables predicted (see Appendix S2). According median error values were highest for soil reaction $(0.38)$ and correlated nutrients (0.27) and humus (0.26). The individual error values at a site did not exceed 0.45 . Thus model estimates did not equal the maximum explanatory power of observed mean indicator values but they deviated within a reasonable range from this optimum. Their explanatory power even rises when we look at groupings of patches instead of single surfaces. The corresponding accuracy increases with the factor $1 / \sqrt{ } n$, where $\mathrm{n}$ is the number of patches being grouped. Thus the final accuracy depends on the respective model performance and the spatial aggregation being looked at. Calculating the mean indicator value of the whole mire area produces the most accurate estimate.

Predictive potential of fine-scale topo-structure

Given the primary role of spectral predictors in many stand level vegetation mapping approaches (Govender et al. 2007; Judd et al. 2007), the overall competitive predictive power of the LIDAR information was striking. It was particularly good at predicting the correlated gradients moisture, dispersion and, above all, light, which confirms the expected strong relationship between these gradients and the small-scale relief and vegetation structure of our mire sites. However, the actual benefit of the topo-structural data was demonstrated by the full model versions when they supplied important additional information that was not part of the spectral reflectance data. These extra contributions from LIDAR data differed with different indicators and spectral counterparts. In general, the enhancements were most distinct with ADS40, indicating higher complementation effects than with RC30 or even SPOT5 data.

Landolt indicator values have already been mapped across mire habitats (Küchler et al. 2004; Ecker et al. 2008) based on a combination of RC30 and surface data (DTM25 and VHSR DSM). Both studies yielded limited mapping qualities for moisture, as they did not include small-scale terrain information for areas covered by tree canopies.

Predictive potential of the spectral sensors

The ADS40 sensor set competed successfully with the RC30 sensor when supplemented with the topo-structure data. We conclude that the strengths and weaknesses of each spectral sensor concerning flight date, angles and resolution aspects resulted in differing partial model contributions but were largely compensated for by the additional LIDAR data. Controlled flight dates and the introduction of the new generation of sensor heads (SH52), providing all colour bands in the nadir viewing angle, might still improve the predictive power of the ADS40 data. The switch from using the analogue film camera RC30 to the digital scanner system ADS40 would certainly considerably reduce the pre-processing efforts required in photogrammetry.

The space-borne SPOT5 sensor suffered from adverse spectral resolution and colour quality as well as from uncontrolled recording dates. Consequently, the mapping quality of the partial SPOT5 model was clearly the lowest across all indicator values. Surprisingly, it benefited less from adding the TOPO predictor set than the ADS40 data, and conversely provided hardly any supplementary information to the TOPO data except for moisture. However, the SPOT5 sensor theoretically permits the mapping of mires over large areas of $60 \mathrm{~km}$. Thus, pooling the training data from all mire sites covered by a scene might compensate for the low predictive power of the sensor. In this study, fitting a single model across all seven mire habitats was not appropriate as the tested SPOT5 image represented a composite of three individual radiometrically inconsistent scenes taken on different days in 2005.

\section{Ecological interpretation of the spectral contributions}

Spectral signals are considered surrogates that integrate many ecosystem processes and properties (Ustin et al. 2004). The concentrations of foliar pigments in single leaves such as chlorophyll and carotenoid have been shown to be directly related to the fractions of absorbed radiation in the photosynthetically active range between 400 and $720 \mathrm{~nm}$. Other absorption centres between 970 and $1,900 \mathrm{~nm}$ are related to plant water concentrations (Bannari et al. 1995). Accordingly, the reflectance spectra provide information on the physiological status and the assimilatory capacity of the vegetation. However, the vegetation reflectance varies with the sun-sensor geometry and the spatio-structure of the canopy (clumping of foliage, leaf angle distribution, spatial distribution of plants, etc.). Additional variations arise from interfering factors such as bare soil, litter, woody parts, surrounding features and atmosphere. This noise has to be taken into account when retrieving physiological vegetation properties (Malenovsky et al. 2009). When mapping of floristic gradients is aimed at, the disentanglement of the canopy and background reflectance is not required. Here, we took advantage of the 
whole information by filtering the informative parts via empirical regression models.

The present study explored the predictive potential of three spectral recording systems. Results (median $r^{2}$ ) showed differences in their relative sensitivities, though all spectral sensors tended to better reflect the gradients correlated with nutrients (nutrients, humus, soil reaction) than with moisture (moisture, dispersion). This trend was most pronounced in the RC30 data and still distinct in the SPOT5 data but less clear in the ADS40 data. Since the spectral data sets did not cover the NIR ranges which are sensitive to water concentrations $(970-1,900 \mathrm{~nm})$, the restricted predictive power for moisture and dispersion was in line with expectations. Even the hyperspectral data based models mentioned above (Schmidtlein and Sassin 2004; Schmidtlein 2005) resulted in better predictions for soil reaction $(0.76,0.68)$ and nutrients $(0.75,0.66)$ than for moisture $(0.66,0.58)$, again with respect to $r_{\mathrm{cv}}^{2}$. However, the ADS40 data might have profited from the additional blue colour band when relatively successfully predicting moisture.

Other differences are subject to more speculation. The relatively good performance of the satellite data when predicting nutrients and humus might result from the big patch size of the gradient representatives (bog, nutrient rich grassland). The relatively poor prediction capacity of the ADS40 data for nutrients, humus and reaction might be attributed to flight dates being less controlled for sun position and phenology. The unstable ranking of the airborne sensors when predicting these gradients suggests such a background. At least the striking inferiority of the ADS40 data in object 64 is clearly related to an adverse sun position and pronounced topographic shading. The clear disadvantage of the same sensor when predicting light and temperature supports the impression of less favourable recording conditions being the limiting factor.

The benefit of adding spectral data to environmental information has been investigated in the context of species distribution modelling. Thuiller et al. (2004) and Zimmermann et al. (2007) modelled species across a forested mountain region and all over Europe and identified bioand topo-climate as the major predictors. The coarsegrained spectral satellite data used enhanced the model fit but did not improve the cross-validated model accuracy. Pearson et al. (2004) modelled species distribution in Great Britain and made significant improvements by adding spectral information, which enabled regions with suitable climate but unsuitable land cover to be identified. In our study, whether adding spectral data to topo-structure led to improvements depended on the spatial resolution used and the feature type addressed.

Being combined with environmental predictors, spectral reflectance provides unique information about process-level characteristics related to phenology or succession, such as biomass and productivity. Zimmermann et al. (2007) ascertained that species with a strong phenological signal, such as early successional and broadleaf deciduous trees, benefited most from including multi-temporal spectral images for distribution modelling. In this study the improvements from adding spectral information were highest when mapping the highly correlated gradients soil reaction, nutrients and humus. We interpret the additional contributions as reflecting biomass and productivity-related processes that are not explained by topo-structure.

\section{Conclusion}

The aim of this study was to assess the individual and combined contributions of different sensor types to the stand-level mapping of plant-indicator gradients across mire habitats. The two airborne multi-spectral images were found to have similar potential when combined with topo-structure. This means the traditional and labourintensive RC30 photographs could be replaced by digital ADS40 images without sacrificing any relevant prediction quality. However, topo-structural predictors were mostly as good as or clearly outperformed the predictive power of pure spectral reflectance data on all indicator values predicted. Adding topo-structure to the spectral predictors yielded considerable benefits for all indicator values and spectral sensors involved, although the ADS40 data clearly benefited most. Conversely, adding spectral signals to topo-structure particularly improved the prediction success for soil reaction, nutrients and humus. However, the SPOT5 data provided hardly any supplementary information to topo-structure. These findings should help related studies estimate the investments in remote sensing data needed to achieve pre-defined mapping standards. The additional contributions of the individual sensor types also give an impression of the degree to which individual plant-indicator gradients are controlled by the static environment and canopy height alone or by other ecological processes. The type of relationship between plant-indicator gradients and spectral reflectance still needs to be elucidated, especially when the effect of topostructure is controlled for. Imaging spectroscopy has great potential for improving our understanding of the ecological factors reflected by spectral reflectance (Ustin et al. 2004).

Acknowledgments We are grateful to Otto Wildi and Elizabeth Feldmeyer-Christe for critical feedback on the paper and to Silvia Dingwall and Peter Longatti for the English revision. The monitoring program was funded by the Swiss Federal Office for the Environment FOEN. 


\section{References}

Alexandridis TK, Lazaridou E, Tsirika A, Zalidis GC (2009) Using earth observation to update a Natura 2000 habitat map for a wetland in Greece. J Environ Manag 90:2243-2251

Atzberger C (2004) Object-based retrieval of biophysical canopy variables using artificial neural nets and radiative transfer models. Remote Sens Environ 93:53-67

Bannari A, Morin D, Bonn F, Huete AR (1995) A review of vegetation indices. Remote Sens Rev 13:95-120

Barducci A, Guzzi D, Marcoionni P, Pippi I (2009) Aerospace wetland monitoring by hyperspectral imaging sensors: a case study in the coastal zone of San Rossore Natural Park. J Environ Manag 90:2278-2286

Baret F, Guyot G (1991) Potentials and limits of vegetation indexes for LAI and APAR assessment. Remote Sens Environ 35:161-173

Bunce RGH, Metzger MJ, Jongman RHG, Brandt J, De Blust G, Elena-Rossello R, Groom GB, Halada L, Hofer G, Howard DC, Kovar P, Mucher CA, Padoa-Schioppa E, Paelinx D, Palo A, Perez-Soba M, Ramos IL, Roche P, Skanes H, Wrbka T (2008) A standardized procedure for surveillance and monitoring European habitats and provision of spatial data. Landsc Ecol 23:11-25

Cramer M (2005) Digital airborne cameras-status and future. In: ISPRS Workshop "High Resolution Earth Imaging for Geospatial Information". Hannover

Diekmann M (2003) Species indicator values as an important tool in applied plant ecology—a review. Basic Appl Ecol 4:493-506

Dudoit S, van der Laan MJ (2008) Multiple testing procedures with applications to genomics. Springer, New York

Ecker K, Küchler M, Feldmeyer-Christe E, Graf U, Waser LT (2008) Predictive mapping of floristic site conditions across mire habitats: evaluating data requirements. Community Ecol 9:133-146

Ellenberg H (1974) Zeigerwerte der Gefässpflanzen Mitteleuropas. Scr Geobot 9:97

Ellenberg H, Webwe HE, Düll R, Wirth V, Werner W, Paulissen D (1992) Zeigerwerte von Pflanzen in Mitteleuropa. Scr Geobot $18: 258$

Feldmeyer-Christe E, Ecker K, Kuchler M, Graf U, Waser L (2007) Improving predictive mapping in Swiss mire ecosystems through re-calibration of indicator values. Appl Veg Sci 10:183-192

Gilmore MS, Wilson EH, Barrett N, Civco DL, Prisloe S, Hurd JD, Chadwick C (2008) Integrating multi-temporal spectral and structural information to map wetland vegetation in a lower Connecticut River tidal marsh. Remote Sens Environ 112:4048_ 4060

Govender M, Chetty K, Bulcock H (2007) A review of hyperspectral remote sensing and its application in vegetation and water resource studies. Water SA (Pretoria) 33:145-151

Graf U, Küchler M, Ecker K, Feldmeyer-Christe E, Grosvernier P, Berchten F, Lugon A, David R, Marti F (2007) Zustand und Entwicklung der Moore in der Schweiz. Ergebnisse der Erfolgskontrolle Moorschutz. In: Klaus G (ed) Umwelt-Zustand Nr. 0730. Bundesamt für Umwelt, Bern, p 97

Grünig A, Steiner GM, Ginzler C, Graf U, Küchler M (2005) Approaches to swiss mire monitoring/Vorschläge für das MoorMonitoring in der Schweiz. Stapfia 85:435-452

Harris A, Bryant RG (2009) A multi-scale remote sensing approach for monitoring northern peatland hydrology: present possibilities and future challenges. J Environ Manag 90:2178-2188

Houborg R, Soegaard H, Boegh E (2007) Combining vegetation index and model inversion methods for the extraction of key vegetation biophysical parameters using Terra and Aqua MODIS reflectance data. Remote Sens Environ 106:39-58
Huete A, Didan K, Miura T, Rodriguez EP, Gao X, Ferreira LG (2002) Overview of the radiometric and biophysical performance of the MODIS vegetation indices. Remote Sens Environ 83:195213

Jacquemoud S, Bacour C, Poilve H, Frangi JP (2000) Comparison of four radiative transfer models to simulate plant canopies reflectance: direct and inverse mode. Remote Sens Environ 74:471-481

Jensen JLR, Humes KS, Vierlin LA, Hudak AT (2008) Discrete return lidar-based prediction of leaf area index in two conifer forests. Remote Sens Environ 112:3947-3957

Johansen K, Coops NC, Gergel SE, Stange Y (2007) Application of high spatial resolution satellite imagery for riparian and forest ecosystem classification. Remote Sens Environ 110:29-44

Jones K, Lanthier Y, van der Voet P, van Valkengoed E, Taylor D, Fernandez-Prieto D (2009) Monitoring and assessment of wetlands using earth observation: the GlobWetland project. J Environ Manag 90:2154-2169

Judd C, Steinberg S, Shaughnessy F, Crawford G (2007) Mapping salt marsh vegetation using aerial hyperspectral imagery and linear unmixing in Humboldt bay, California. Wetlands 27:1144-1152

Kellenberger TW, Nagy P (2008) Potential of the ADS40 Aerial Scanner for archaeological prospection in Rheinau, Switzerland. In: XXI congress international society for photogrammetry and remote sensing. Beijing, China

Korpela I, Koskinen M, Vasander H, Holopainen M, Minkkinen K (2009) Airborne small-footprint discrete-return LiDAR data in the assessment of boreal mire surface patterns, vegetation, and habitats. For Ecol Manag 258:1549-1566

Küchler M, Ecker K, Feldmeyer-Christe E, Graf U, Küchler H, Waser LT (2004) Combining remotely sensed spectral data and digital surface models for fine-scale modelling of mire ecosystems. Community Ecol 5:55-68

Küchler M, Ecker K, Feldmeyer E, Graf U, Waser LT (2007) Predictive models of mire habitats: bias in detection of changes. In: Kubrak J, Okruszko T, Ignar S (eds) Wetlands: monitoring, modelling and management. Taylor \& Francis, London, pp 91-100

Landolt E (1977) Ökologische Zeigerwerte zur Schweizer Flora. Veröffentlichungen des Geobotanischen Institutes der Eidg. Techn. Hochschule, Stiftung Rübel, Zürich

MacAlister C, Mahaxay M (2009) Mapping wetlands in the Lower Mekong Basin for wetland resource and conservation management using Landsat ETM images and field survey data. J Environ Manag 90:2130-2137

MacKay H, Finlayson CM, Fernandez-Prieto D, Davidson N, Pritchard D, Rebelo LM (2009) The role of earth observation (EO) technologies in supporting implementation of the Ramsar Convention on Wetlands. J Environ Manag 90:2234-2242

Malenovsky Z, Mishra KB, Zemek F, Rascher U, Nedbal L (2009) Scientific and technical challenges in remote sensing of plant canopy reflectance and fluorescence. J Exp Bot 60:2987-3004

McMorrow JM, Cutler MEJ, Evans MG, Al-Roichdi A (2004) Hyperspectral indices for characterizing upland peat composition. Int J Remote Sens 25:313-325

Miller RG (1981) Simultaneous statistical inference, 2nd edn. Springer, New York

Mosteller F, Tukey JW (1977) Data analysis and regression: a second course in statistics. Addison-Wesley, Reading

Pearson RG, Dawson TP, Liu C (2004) Modelling species distributions in Britain: a hierarchical integration of climate and landcover data. Ecography 27:285-298

Petrie G, Walker AS (2007) Airborne digital imaging technology: a new overview. Photogramm Rec 22:203-225

Qi J, Chehbouni A, Huete AR, Kerr YH, Sorooshian S (1994) A modified soil adjusted vegetation index. Remote Sens Environ 48:119-126 
Richardson AJ, Everitt JH (1992) Using spectral vegetation indices to estimate rangeland productivity. Geocarto Int 1:63-69

Richardson AJ, Wiegand CL (1977) Distinguishing vegetation from soil background information. Photogramm Eng Remote Sens 43:1541-1552

Rydin H, Eglum JK (2006) Biology of peatlands. Oxford University Press, Oxford

Schmidtlein S (2005) Imaging spectroscopy as a tool for mapping Ellenberg indicator values. J Appl Ecol 42:966-974

Schmidtlein S, Sassin J (2004) Mapping of continuous floristic gradients in grasslands using hyperspectral imagery. Remote Sens Environ 92:126-138

Straatsma MW, Baptist M (2008) Floodplain roughness parameterization using airborne laser scanning and spectral remote sensing. Remote Sens Environ 112:1062-1080

Thuiller W, Araujo MB, Lavorel S (2004) Do we need land-cover data to model species distributions in Europe? J Biogeogr 31:353-361

Ustin SL, Roberts DA, Gamon JA, Asner GP, Green RO (2004) Using imaging spectroscopy to study ecosystem processes and properties. Bioscience 54:523-534

Verrelst J, Geerling GW, Sykora KV, Clevers J (2009) Mapping of aggregated floodplain plant communities using image fusion of CASI and LiDAR data. Int J Appl Earth Obs Geoinf 11:83-94
Waser LT, Baltsavias E, Ecker K, Eisenbeiss H, Ginzler C, Küchler M, Thee P, Zhang L (2008a) High-resolution digital surface models (DSMs) for modelling fractional shrub/tree cover in a mire environment. Int J Remote Sens 29:1261-1276

Waser LW, Eisenbeiss H, Kuechler M, Baltsavias B (2008b) Potential and limits of airborne remote sensing data for extraction of fractional canopy cover and forest stands and detection of tree species. In: The international archives of the photogrammetry, remote sensing and spatial information sciences, vol XXXVII. Part B8. Beijing, pp 1405-1412

Wiegand CL, Richardson AJ, Escobar DE, Gerbermann AH (1991) Vegetation indexes in crop assessments. Remote Sens Environ $35: 105-119$

Wold S, Trygg J, Berglund A, Antti H (2001) Some recent developments in PLS modeling. Chemom Intell Lab Syst 58:131-150

Zimmermann NE, Edwards TCJ, Moisen GG, Frescino TS, Blackard JA (2007) Remote sensing based predictors improve distribution models of rare, early successional and broadleaf tree species in Utah. J Appl Ecol 44:1057-1067 